\title{
Plasma Cell Cerebrospinal Fluid Pleocytosis Does Not Predict West Nile Virus Infection
}

\author{
Michael Jordan, ${ }^{1}$ Avish Nagpal, ${ }^{2}$ William Newman, ${ }^{1}$ Paul A. Thompson, ${ }^{3}$ \\ and Paul J. Carson', 4 \\ ${ }^{1}$ Department of Internal Medicine, School of Medicine and Health Sciences, University of North Dakota, Grand Forks, \\ ND 58202, USA \\ ${ }^{2}$ Department of Infectious Disease, Mayo Clinic, Rochester, MN 55905, USA \\ ${ }^{3}$ Sanford Research/USD, Sanford Health, Sioux Falls, SD 57104, USA \\ ${ }^{4}$ Department of Infectious Disease, Sanford Health, Fargo, ND 58122, USA
}

Correspondence should be addressed to Paul J. Carson, paul.carson@sanfordhealth.org

Received 25 May 2011; Accepted 30 July 2011

Academic Editor: Stuart D. Blacksell

Copyright (C) 2012 Michael Jordan et al. This is an open access article distributed under the Creative Commons Attribution License, which permits unrestricted use, distribution, and reproduction in any medium, provided the original work is properly cited.

\begin{abstract}
Purpose. Diagnosis of WNV (WNV) relies upon serologic testing which may take several days after the onset of clinical symptoms to turn positive. Anecdotal reports suggest the presence of plasma cells or plasmacytoid lymphocytes in the cerebrospinal fluid (CSF) may be an early indicator of WNV infection. Methods. The CSFs of 89 patients (12 with WNV, 12 with other viral illness $\{\mathrm{OVI}\}$, and 65 with nonviral illness $\{\mathrm{NVI}\}$ ) were compared for the presence of either plasma cells or plasmacytoid lymphocytes. Results. Plasma cells were rarely seen in any of the patients. Plasmacytoid lymphocytes were more commonly seen in WNV (58\%) and OVI (50\%) than NVI (11\%). The differences were significant for WNV versus NVI, but not WNV versus OVI $(P<0.001$ and $P=0.58$, resp.). Conclusions. A CSF pleocytosis with plasma cells or plasmacytoid lymphocytes was neither sensitive nor specific for the diagnosis of WNV infection.
\end{abstract}

\section{Introduction}

West Nile virus, a mosquito-borne flavivirus, first appeared in North America in the New York City metropolitan area in 1999. Since that time, the ArboNET surveillance system has documented the virus' dramatic spread across the United States with 30,662 cases of WNV disease reported from 47 states through $2010[1,2]$. Over 11000 cases were classified as West Nile neuroinvasive disease (WNND), and over 1000 of these cases died with their infection. WNV has now become the leading cause of arboviral encephalitis in the United States with likely ongoing seasonal epidemic transmission [2].

Symptoms of WNV infection are nonspecific, and definitive diagnosis rests on finding WNV RNA in CSF or blood, or more commonly, serologic evidence of recent infection as evidenced by the presence of IgM-specific antibodies to WNV antigens in CSF or blood. However, this test may not turn positive until 8-21 days after the first appearance of symptoms [3]. Finding earlier indicators for WNV would facilitate making a more rapid diagnosis. In the setting of meningitis or encephalitis, previous anecdotal reports have suggested the presence of plasma cells or plasmacytoid lymphocytes in CSF may be an early indicator of WNV infection [4-7]. Plasma cells originate in the bone marrow as B cells and after antigenic stimulation undergo differentiation in the lymph node from lymphocyte to plasmacytoid lymphocyte to the plasma cell capable of producing large amounts of antibodies. WNV is known to induce a brisk antibody response that is largely responsible for clearing of the virus $[8,9]$. It is not clear that the cells previously observed in the aforementioned studies are truly plasma cells. In one study of transplant patients with WNV infection, five patients had cytology performed on the CSF that showed atypical lymphocytes and plasma cells. However, flow cytometry was performed on 3 of these patients which showed the cells were predominantly mature $\mathrm{T}$ cells with only negligible $\mathrm{B}$ cells present [7]. 
TABLE 1: CSF cell count findings in WNV-infected patients versus patients with other viral illness (OVI) or non-viral illness (NVI).

\begin{tabular}{|c|c|c|c|c|c|c|c|}
\hline \multirow{2}{*}{ Variable } & \multirow{2}{*}{$\begin{array}{l}\text { Display } \\
\text { meaning }\end{array}$} & \multirow{2}{*}{ WNV infection } & \multirow{2}{*}{$\begin{array}{l}\text { Other viral } \\
\text { illness }\end{array}$} & \multirow{2}{*}{ Non-viral illness } & \multicolumn{3}{|c|}{$P$ values for tests } \\
\hline & & & & & Overall & $\begin{array}{c}\text { WNV } \\
\text { versus } \\
\text { OVI }\end{array}$ & $\begin{array}{c}\text { WNV } \\
\text { versus } \\
\text { NVI }\end{array}$ \\
\hline Total & $N$ & $n=12$ & $n=12$ & $n=65$ & - & - & - \\
\hline Gender & M & 50.0 & 50.0 & 50.8 & 0.98 & - & - \\
\hline Age & Mean (SD) & $51.2(17.5)$ & $37.1(16.1)$ & $35.5(27.1)$ & 0.13 & - & - \\
\hline $\mathrm{RBC}$ & Mean (SD) & $42.3(53.3)$ & $642.3(2095.3)$ & $28858.4(179338.1)$ & 0.74 & 0.99 & 0.55 \\
\hline WBC & Mean (SD) & $236.7(265.1)$ & $325.0(446.0)$ & $174.9(561.6)$ & 0.64 & 0.68 & 0.71 \\
\hline \% Lymphocytes & Mean (SD) & $41.6(27.1)$ & $53.9(28.9)$ & $58.2(30.7)$ & 0.22 & 0.32 & 0.08 \\
\hline \% Monocytes & Mean (SD) & $12.0(5.8)$ & $25.8(20.1)$ & $18.8(19.3)$ & 0.19 & 0.07 & 0.24 \\
\hline \% Neutrophils & Mean (SD) & $44.4(28.9)$ & 18. $7(29.8)$ & $23.1(30.8)$ & 0.07 & 0.04 & 0.03 \\
\hline \% PC lymphocytes & Mean (SD) & $1.8(2.1)$ & $1.1(1.4)$ & $0.1(0.4)$ & $<.0001$ & 0.06 & $<.0001$ \\
\hline$\%$ Plasma Cells & Mean (SD) & $0.2(0.6)$ & $0.3(0.7)$ & $0.1(0.4)$ & 0.30 & 0.38 & 0.69 \\
\hline PC lymphocytes present & $N(\%)$ & $7 / 12(58.3)$ & $6 / 12(50.0)$ & $7 / 65(10.8)$ & $<.0001$ & 0.58 & $<.0001$ \\
\hline Plasma Cells present & $N(\%)$ & $1 / 12(8.3)$ & $3 / 12(25.0)$ & $5 / 65(7.7)$ & 0.18 & 0.17 & 0.94 \\
\hline
\end{tabular}

We sought to determine the utility of the anecdotal finding of plasma cell CSF pleocytosis by calculating sensitivity and specificity among a larger group of patients undergoing lumbar puncture for a variety of indications.

\section{Subjects and Methods}

From June 2007 to August 2008, slides submitted to our laboratory for CSF cell counts were saved for future investigation. Patients were excluded if they were under the age of 1 month or had a known immunosuppressive condition. Eighty-nine slides had enough cells present to be able to do a 100cell differential count. Subject's records were reviewed for the final diagnosis pertaining to the lumbar puncture, CSF white blood cell (WBC) count, red blood cell (RBC) count, WBC differential, and WNV test results (if done). Slides were then reviewed with a 100-cell differential count specifically looking for the presence of plasma cells or plasmacytoid lymphocytes based on standard morphologic criteria [10]. Only one person reviewed all the slides and was blinded to the patient's diagnosis.

Patients with WNV were compared for the presences of plasma cells or plasmacytoid lymphocytes in the CSF to patients with other viral illness and those without any presumed CNS infection. Differences between groups were tested using generalized linear methods (for binomial variables) or ANOVA methods (for continuous variables), with contrasts used to test differences between groups within the overall three-group difference. Differences were also examined using nonparametric methods, with equivalent results. Tests were performed using SAS V. 9.2 software.

\section{Results}

Twelve patients tested positive for WNV by IgM capture ELISA. Five of the WNV patients had meningoencephalitis, 7 had just meningitis. Twelve other patients were thought to have a viral illness other than WNV. Eleven of these patients had negative testing for the presence of WNV-specific IgM antibodies in serum, and 6 had specific other viral infections diagnosed (3 with enterovirus, 2 with herpes simplex type II, and one with Epstein-Barr virus). Details of the CSF findings for WNV patients versus patients with other viral illnesses versus patients with no presumed infection are summarized in Table 1 . WNV patients were older and more likely to have neutrophils in their CSF. When compared to patients without presumed infection, they were more likely to have plasmacytoid lymphocytes in their CSF. However, the sensitivity of this finding was relatively low (58\%), and the overall percentage of plasmacytoid lymphocytes was relatively low (mean of $1.8 \%$ ). However, when patients with WNV were compared only to patients with other viral infection, finding plasmacytoid lymphocytes was not specific for WNV. Six out of twelve patients with other viral syndromes had plasmacytoid lymphocytes present, suggesting a specificity of only 50\%. The presence of plasma cells was rare in WNV patients (only 1/12) and was actually more common in the other viral illnesses (3/12). Combining the presence of plasma cells and plasmacytoid lymphocytes did not enhance sensitivity or specificity. If we compared the WNV encephalitis patients with the WNV meningitis patients, plasmacytoid lymphocytes were seen rarely in the encephalitis cases $(1 / 5)$ whereas they were frequently seen in the meningitis cases $(6 / 7)$.

\section{Discussion}

Our study did not confirm earlier anecdotal findings that plasma cells or plasmacytoid lymphocytes may be an early marker for WNV infection. The overall sensitivity of this finding was only $58 \%$. The sensitivity increased to $86 \%$ if one excluded the WNV encephalitis cases and only considered the WNV meningitis cases. However, this may be a spurious finding due to the low numbers of subjects in either group. 
All of the encephalitis cases also had meningitis with nearly equivalent numbers of total WBCs in the CSF, so a distinction between these clinical entities which lie on a spectrum of illness would seem unlikely. Most importantly, this finding was seen in several of our patients with other forms of viral meningitis, thus suggesting a significant lack of specificity.

It is likely that the presence of plasma cells or plasmacytoid lymphocytes is simply a nonspecific marker of central nervous system infection. Of note is that, in our prior reported case series of 4 patients, all had underlying conditions causing variable degrees of immunosuppression: myelodysplasia, myeloproliferative disorder, Graves' disease, and renal/pancreas transplantation. This suggests that immunosuppression may have played a role in the development of the plasma cell pleocytosis.

It should be noted that plasma cells and plasmacytoid lymphocytes have been noted in the CSF of several other infections including HIV [11], tuberculous meningitis [12], neuroborreliosis [13], neurocysticercosis [14], secondary syphilis [15], herpes zoster meningoencephalitis [16], and African sleeping sickness [17]. Furthermore, the morphologic characterization of what constitutes a plasma cell or plasmacytoid lymphocyte is somewhat subjective and, therefore, technician dependent. One might expect further diminishing of specificity in real-life conditions where different laboratory technicians would be interpreting these cell differentials variably.

\section{Conclusions}

The finding of plasma cells or plasmacytoid lymphocytes in the CSF was neither sensitive nor specific for the diagnosis of West Nile virus infection. Other modalities or improvements in current laboratory testing will need to be sought if we hope to improve on the timeliness of diagnosing acute WNV infection.

\section{Conflict of Interests}

There is no conflict of interests to report among any of the authors, and all authors had full access to the data and participated in the preparation and review of the paper.

\section{References}

[1] L. R. Petersen and E. B. Hayes, "Westward ho? - the spread of West Nile virus," The New England Journal of Medicine, vol. 351, no. 22, pp. 2257-2259, 2004.

[2] N. P. Lindsey, J. E. Staples, J. A. Lehman, and M. Fischer, "Surveillance for human West Nile virus disease-United States, 1999-2008," Morbidity and Mortality Weekly Report Surveillance Summaries, vol. 59, no. 2, pp. 1-17, 2010.

[3] S. L. Rossi, T. M. Ross, and J. D. Evans, "West Nile virus," Clinics in Laboratory Medicine, vol. 30, no. 1, pp. 47-65, 2010.

[4] P. J. Carson, T. Steidler, R. Patron, J. M. Tate, R. Tight, and R. A. Smego Jr., "Plasma cell pleocytosis in cerebrospinal fluid in patients with West Nile virus encephalitis," Clinical Infectious Diseases, vol. 37, no. 1, pp. e12-e15, 2003.

[5] K. M. Chan-Tack and G. Forrest, "A man with fever, headache, and confusion," Clinical Infectious Diseases, vol. 39, no. 12, pp. 1834-1857, 2004.
[6] L. E. Davis, R. DeBiasi, D. E. Goade et al., "West Nile virus neuroinvasive disease," Annals of Neurology, vol. 60, no. 3, pp. 286-300, 2006.

[7] B. K. Kleinschmidt-DeMasters, B. A. Marder, M. E. Levi et al., "Naturally acquired West Nile virus encephalomyelitis in transplant recipients: clinical, laboratory, diagnostic, and neuropathological features," Archives of Neurology, vol. 61, no. 8, pp. 1210-1220, 2004.

[8] M. S. Diamond, B. Shrestha, E. Mehlhop, E. Sitati, and M. Engle, "Innate and adaptive immune responses determine protection against disseminated infection by West Nile encephalitis virus," Viral Immunology, vol. 16, no. 3, pp. 259278, 2003.

[9] H. E. Prince, L. H. Tobler, M. Lapé-Nixon, G. A. Foster, S. L. Stramer, and M. P. Busch, "Development and persistence of West Nile Virus-specific immunoglobulin M (IgM), IgA, and IgG in viremic blood donors," Journal of Clinical Microbiology, vol. 43, no. 9, pp. 4316-4320, 2005.

[10] R. I. Handin, S. E. Lux, and T. P. Stossel, Blood: Principles and Practice of Hematology, Lippincott Williams and Wilkins, Philadelphia, Pa, USA, 2nd edition, 2003.

[11] L. Hagberg, A. Forsman, G. Norkrans, E. Rybo, and L. Svennerholm, "Cytological and immunoglobulin findings in cerebrospinal fluid of symptomatic and asymptomatic human immunodeficiency virus (HIV) seropositive patients," Infection, vol. 16, no. 1, pp. 13-18, 1988.

[12] Z. Tatomirović, R. Bokun, and Z. Trajković, "Cytologic characteristics of cerebrospinal fluid in patients with serous meningitis caused by enteroviruses, mumps virus or koch's bacillus," Vojnosanitetski Pregled, vol. 52, no. 4, pp. 349-354, 1995.

[13] E. Sindern and J. P. Malin, "Phenotypic analysis of cerebrospinal fluid cells over the course of Lyme meningoradiculitis," Acta Cytologica, vol. 39, no. 1, pp. 73-75, 1995.

[14] G. P. Bravo, T. C. Vázquez, M. M. Polanco, R. G. Quezada, and B. E. Vidal, "Plasma cells in the cerebrospinal fluid of patients with cerebral cysticercosis," Revista de Investigacion Clinica, vol. 42, no. 1, pp. 23-28, 1990.

[15] O. J. Kolar and J. E. Burkhart, "Neurosyphilis," British Journal of Venereal Diseases, vol. 53, no. 4, pp. 221-225, 1977.

[16] H. Shoji and D. Dommasch, "Zoster meningitis and radiculomeningitis after tick bite. Cytological findings in cerebrospinal fluid," European Neurology, vol. 18, no. 3, pp. 149156, 1979.

[17] V. W. Pentreath, P. J. Baugh, and D. R. Lavin, "Sleeping sickness and the central nervous system," The Onderstepoort journal of Veterinary Research, vol. 61, no. 4, pp. 369-377, 1994. 

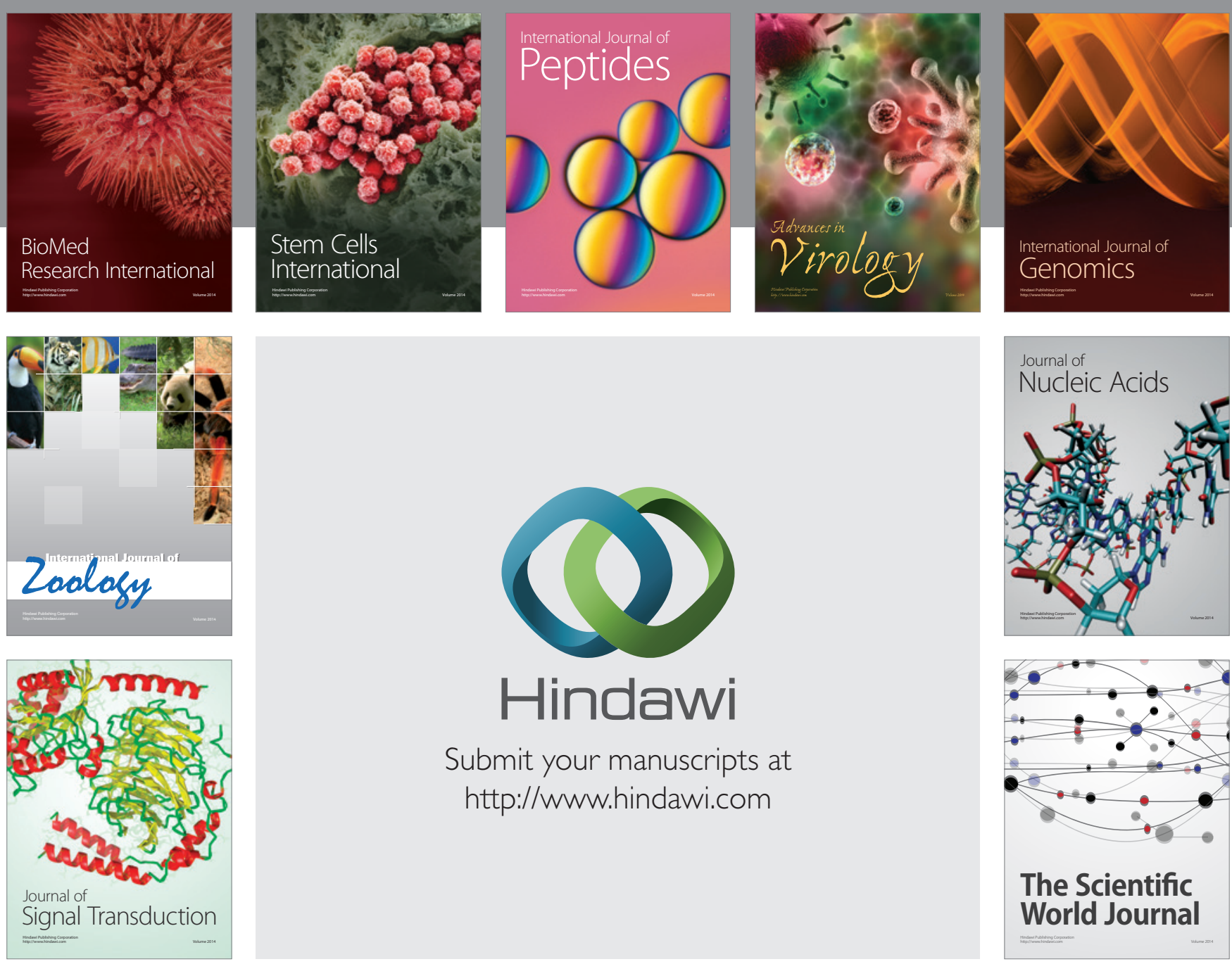

Submit your manuscripts at

http://www.hindawi.com
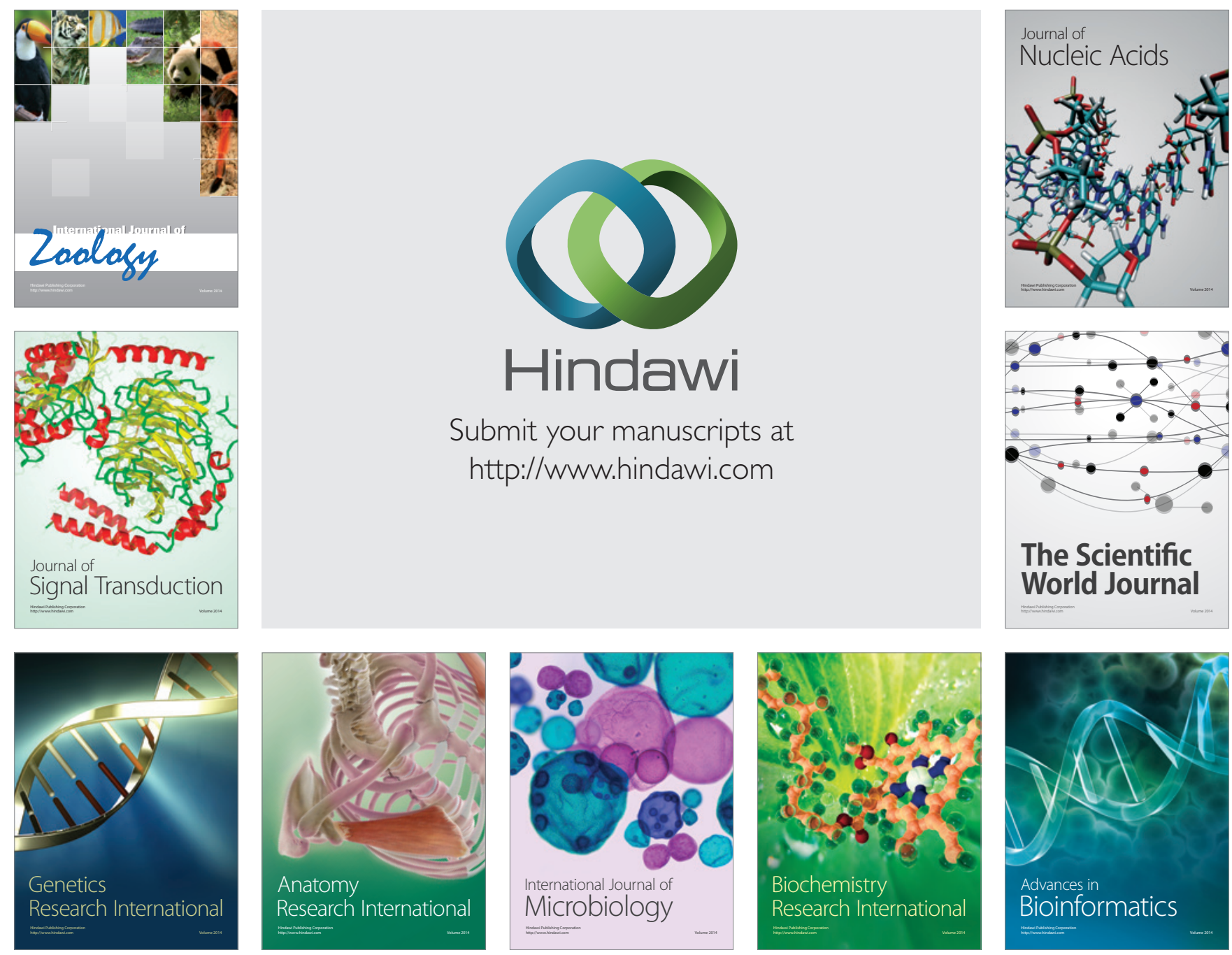

The Scientific World Journal
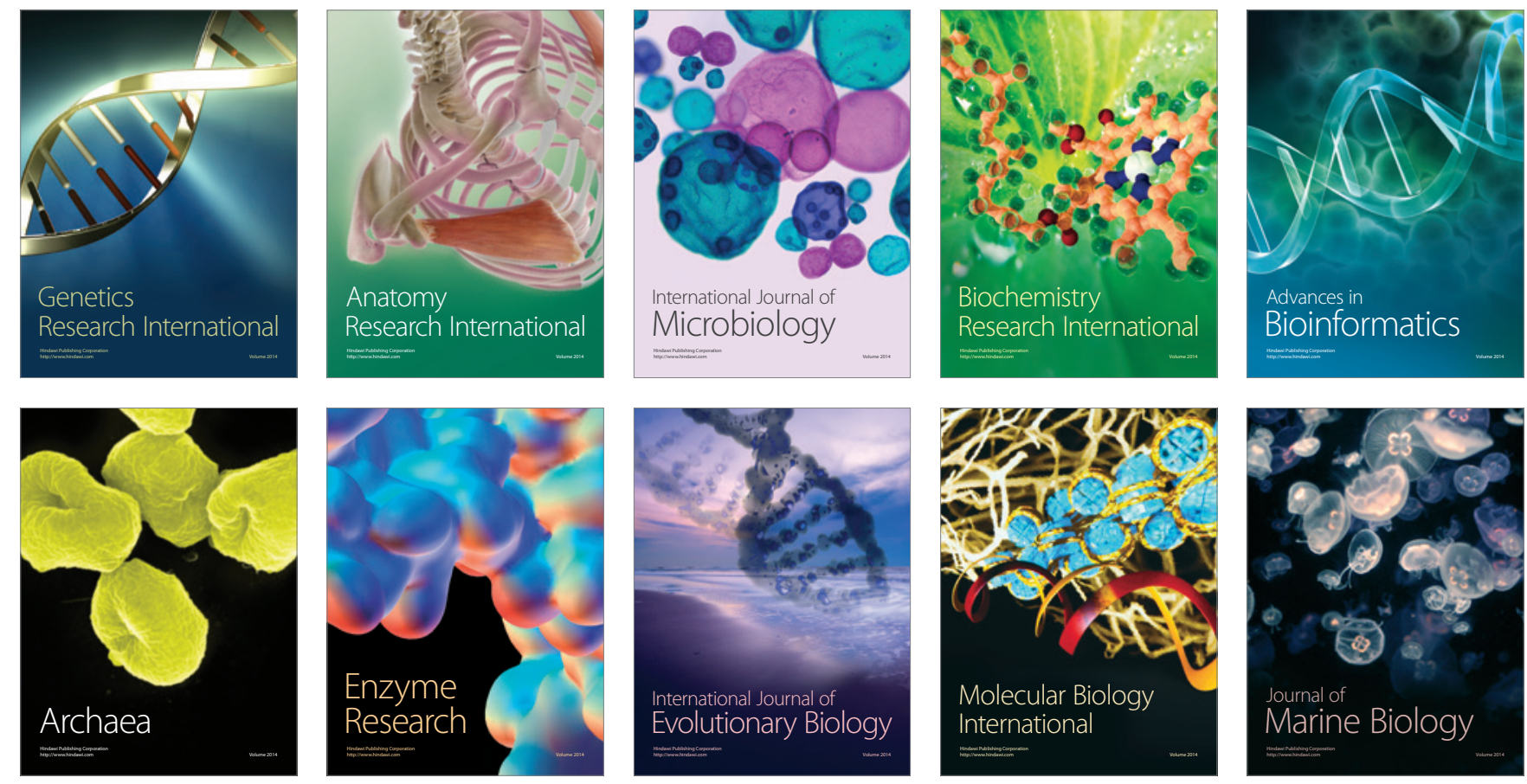